\title{
Both high and low serum vitamin D concentrations are associated with tuberculosis: a case-control study in Greenland
}

\author{
Nina O. Nielsen ${ }^{1}$, Turid Skifte ${ }^{2}$, Mikael Andersson ${ }^{1}$, Jan Wohlfahrt ${ }^{1}$, Bolette Søborg ${ }^{1}$, Anders Koch $^{1}$, \\ Mads Melbye ${ }^{1}$ and Karin Ladefoged ${ }^{3}$ \\ ${ }^{1}$ Department of Epidemiology Research, Statens Serum Institut, Copenhagen, Denmark \\ ${ }^{2}$ National Board of Health in Greenland, Nuuk, Greenland \\ ${ }^{3}$ Medical Department, Queen Ingrid's Hospital, Nuuk, Greenland
}

(Received 13 January 2010 - Revised 10 May 2010 - Accepted 12 May 2010 - First published online 17 June 2010)

Vitamin D deficiency has been associated with increased risk of tuberculosis (TB). Changes from a traditional to a Westernised diet among Greenlanders have resulted in reduced serum vitamin D, leading to considerations of whether preventive vitamin D supplementation should be introduced. The association between vitamin D status and TB was examined to assess the feasibility of vitamin D supplementation in Greenland. This was examined in a case-control study involving seventy-two matched pairs of TB patients (cases) and controls aged 8-74 years. Cases were diagnosed with TB during 2004-6 based on clinical findings in combination with either (1) positive Mycobacterium tuberculosis culture, (2) characteristic X-ray abnormalities together with a positive tuberculin skin test or a positive interferon- $\gamma$ release assay or (3) characteristic histology. Controls were individually matched on age ( \pm 5 years), sex and district. Serum 25-hydroxyvitamin D $(25(\mathrm{OH}) \mathrm{D})$ concentrations were measured and OR of TB were the outcome. Compared with individuals with $25(\mathrm{OH}) \mathrm{D}$ concentrations between 75 and $140 \mathrm{nmol} / \mathrm{l}$, individuals with concentrations $<75 \mathrm{nmol} / 1$ (OR 6.5; $95 \%$ CI 1.8, 23.5) or $>140 \mathrm{nmol} / 1(\mathrm{OR} 6 \cdot 5 ; 95 \%$ CI 1.9, 22.2) had higher risks of active TB $(P=0 \cdot 003$; adjustment for alcohol and ethnicity). Supplementing individuals with low vitamin D to normalise serum $25(\mathrm{OH}) \mathrm{D}$ concentrations was estimated to result in a $29 \%$ reduction in the number of TB cases. The study indicated that vitamin D supplementation may be beneficial to individuals with insufficient vitamin D concentrations but may increase the risk of TB among individuals with normal or high concentrations.

Tuberculosis: Vitamin D: Odds ratios: Case-control studies: Greenland

Clinical tuberculosis (TB) is a major public health problem in Greenland $^{(1)}$. After the Second World War, one of the highest incidences (2300 per 100000) in the world was found here. Due to significant national efforts, the incidence of TB in Greenland decreased substantially and reached in 1985 the lowest registered level of 25 per $100000^{(1)}$. Since then the incidence has increased again to an average of seventythree cases per year corresponding to 131 per 100000 during the period $1998-2007^{(2)}$.

TB is caused by the intracellular pathogen Mycobacterium tuberculosis which resides predominantly within macrophages. Paradoxically, macrophage activity is the first type of defence against the $M$. tuberculosis infection ${ }^{(3)}$. Vitamin $\mathrm{D}$ is a modulator of macrophage function and can activate host anti-mycobacterial activity. Its active metabolite, 1,25dihydroxyvitamin $\mathrm{D}\left(1,25(\mathrm{OH})_{2} \mathrm{D}\right)$, may improve the ability of macrophages to inhibit the growth of mycobacteriae ${ }^{(4,5)}$. Hence, susceptibility to TB may be increased by vitamin D deficiency ${ }^{(6,7)}$. Accordingly, a recent systematic meta-analysis concluded that low serum vitamin D concentrations are associated with higher risk of active $\mathrm{TB}^{(8)}$. Thus, it is reasonable to suggest that vitamin D supplementation to individuals exposed to $M$. tuberculosis may be beneficial, especially in populations where vitamin D synthesis in the skin is limited and where vitamin $\mathrm{D}$ intake through the diet is scarce.

In Greenland exposure to sunlight is limited during winter and vitamin $\mathrm{D}$ synthesis in the skin is therefore likely to be low during this season. Moreover, during the last decades significant cultural changes have occurred in Greenland ${ }^{(9)}$, resulting in the fact that many Greenlanders rely on a Westernised diet low in vitamin $\mathrm{D}$, contrasting to the Greenlandic traditional diet consisting of vitamin D-rich fish and sea mammals ${ }^{(10,11)}$. It has been shown that changes from a Greenlandic to a Westernised diet are associated with a reduced vitamin D status $^{(11)}$. The present study was implemented to analyse the association between vitamin D and active TB in Greenland to assess the feasibility of population-based vitamin D supplementation.

\section{Subjects and methods}

\section{Study design and participants}

We performed a case-control study including diagnosed TB patients and matched controls in Greenland. The study was part of a larger investigation which aimed at identifying risk 
factors of TB. Recruitment of participants took place during 2004-6 at thirteen district hospitals along the west, south and east coasts of Greenland. A total of 216 adults were diagnosed with TB in 2004-6. Due to a rapid turnover of authorised staff and laboratory technicians to take care of blood sampling at some district hospitals, it was not possible to include all. Thus, a subsample of $155(71 \%)$ patients was asked and accepted to participate. The selection was determined by the availability of staff to take care of the inclusion procedures at the time of diagnosis and not by any patient characteristics. For each patient it was intended to identify four healthy sex- and age- ( \pm 5 years) matched population controls from the same hospital district. In Greenland, all individuals have a file at the district hospital containing identification details from the Civil Registration System (CPR) register, which contains unique details on all individuals in Denmark and Greenland. Controls were chosen randomly among these files. For four of the 155 patients no matched controls could be identified, for two patients only two controls were identified, and for one patient three controls were identified. Thus, a total of 599 controls were identified. All patients and controls answered questions about ethnicity, weight and height, smoking, alcohol and diet habits, and social status (employment and income source). Individuals were defined as Inuit if both parents and all grandparents were born in Greenland. For the present study the intention was that all patients and one of their four controls should donate a blood sample for vitamin D (25-hydroxyvitamin D; 25(OH)D) measurement. Among the patients, 148 had four identified controls. The one control who provided a blood sample was selected randomly among the four controls. However, for practical reasons it was not possible to obtain a blood sample from all 148 patients and 148 controls. Successful measurement of $25(\mathrm{OH}) \mathrm{D}$ was obtained from seventy-two matched patient and control pairs. Blood samples were collected at all times of the year, and samples from pairs were collected within 1 week to avoid seasonal differences in vitamin D concentration.

The present study was conducted according to the guidelines laid down in the Declaration of Helsinki and all procedures were approved by The Commission for Scientific Research in Greenland. Written informed consent was obtained from all subjects.

\section{Tuberculosis diagnosis}

The inclusion criteria for patients were a TB diagnosis based on clinical findings in combination with either (1) a positive M. tuberculosis culture, (2) characteristic X-ray abnormalities together with either a positive tuberculin skin test by the Mantoux method or a positive interferon- $\gamma$ release assay (Quantiferon Gold test) or (3) characteristic histology. The Greenlandic TB registration did not differentiate between lung and pleural TB; this is why all cases in the respiratory tract are stated as pulmonary. Mycobacteriological analyses were provided by the International Reference Laboratory of Mycobacteriology (Statens Serum Institut, Copenhagen, Denmark).

\section{Measurement of vitamin $D$}

The vitamin D status was assessed by measuring $25(\mathrm{OH}) \mathrm{D}$ as previously described ${ }^{(12)}$. We defined vitamin D insufficiency, mild vitamin $\mathrm{D}$ deficiency, and severe vitamin $\mathrm{D}$ deficiency as serum $25(\mathrm{OH}) \mathrm{D}$ concentrations of $50-75 \mathrm{nmol} / \mathrm{l}$ $(20-30 \mathrm{ng} / \mathrm{ml}), \quad 25-49 \mathrm{nmol} / \mathrm{l} \quad(10-19.6 \mathrm{ng} / \mathrm{ml}) \quad$ and $<25$ $\mathrm{nmol} / \mathrm{l}(<10 \mathrm{ng} / \mathrm{ml})$, respectively, according to previously used definitions ${ }^{(13,14)}$. Serum $25(\mathrm{OH}) \mathrm{D}$ concentrations of $76-140 \mathrm{nmol} / 1(30 \cdot 4-56 \mathrm{ng} / \mathrm{ml})$ and $>140 \mathrm{nmol} / \mathrm{l}(>56 \mathrm{ng} / \mathrm{ml})$ were characterised as normal and high, respectively.

\section{Statistical analysis}

The association between vitamin $\mathrm{D}$ and other potential risk factors and TB were evaluated by unadjusted and adjusted OR estimated by conditional logistic regression using PROC LOGISTIC in SAS (SAS Institute, Inc., Cary, NC, USA). Adjusted OR were adjusted for $25(\mathrm{OH}) \mathrm{D}$, ethnicity and alcohol. Adjustment variables were selected by a backward elimination procedure. Due to particular focus on vitamin $\mathrm{D}$ we also conducted analyses where only $25(\mathrm{OH}) \mathrm{D}$ was in the model while adjusting for all other variables one by one in separate analyses to test for whether these confounded the association between $25(\mathrm{OH}) \mathrm{D}$ and TB. Associations between $25(\mathrm{OH}) \mathrm{D}$ and other potential risk factors were evaluated by $\chi^{2}$ tests. In an additional analysis the $25(\mathrm{OH}) \mathrm{D}$ concentration in cases and controls was compared using the non-parametric Wilcoxon test. Assuming a causal effect of $25(\mathrm{OH}) \mathrm{D}$ on TB we estimated the effect of supplementing the low-25(OH)D group $(<75 \mathrm{nmol} / \mathrm{l})$ to normal concentrations $(76-140 \mathrm{nmol} / \mathrm{l})$ using attributable risk. All statistical analyses were performed with SAS version 9.2 software (SAS Institute, Inc.).

\section{Results}

Of the seventy-two patients, sixty-seven (93\%) were clinically diagnosed with pulmonary TB. Of these, sixty-one patients (91\%) were confirmed by $M$. tuberculosis culture and/or sputum microscopy for acid-fast bacilli (twenty-one $(31 \%)$ by cultures alone, four $(6 \%)$ by sputum microscopy alone, and thirty-six $(54 \%)$ by both). Of the patients, five $(7 \%)$ were diagnosed with extra-pulmonary TB. In one case $(1 \%)$ the TB localisation was not registered. All cases of extrapulmonary TB were culture-confirmed. The mean time from symptom debut to diagnosis was 116 (SD 119) d. The blood sample was taken before treatment start in $29 \%$; among the rest the mean time from treatment start to sample collection was 18 (SD 25.6) d. Among controls with low, normal or high 25(OH)D, 36, 54 and $75 \%$ had eaten fish often $(P=0 \cdot 26)$, respectively, and 9,25 and $38 \%$, respectively, had eaten seal or whale often $(P=0 \cdot 38)$. The respective numbers for patients were $36 \%, 60 \%$ and $57 \%(P=0.19)$ and $20 \%, 35 \%$ and $43 \%(P=0 \cdot 26)$. Multivitamin tablets were taken by one patient and two controls.

The mean age was 39 years and ranged between 8 and 69 years and 8 and 74 years for patients and controls, respectively. Of the patients and controls, 89 and $74 \%$ were Inuit. Non-Inuits had a lower risk of TB (OR $0 \cdot 1 ; 95 \%$ CI 0.02 , $0 \cdot 5)$ compared with Inuits after adjusting for alcohol and $25(\mathrm{OH}) \mathrm{D}$. Individuals with frequent (every day or between one and six times per week) intake of alcohol had a higher risk of TB (OR 3.9; $95 \%$ CI 1.4, 11.2) compared with individuals with a non-frequent (less than once per week) intake after 


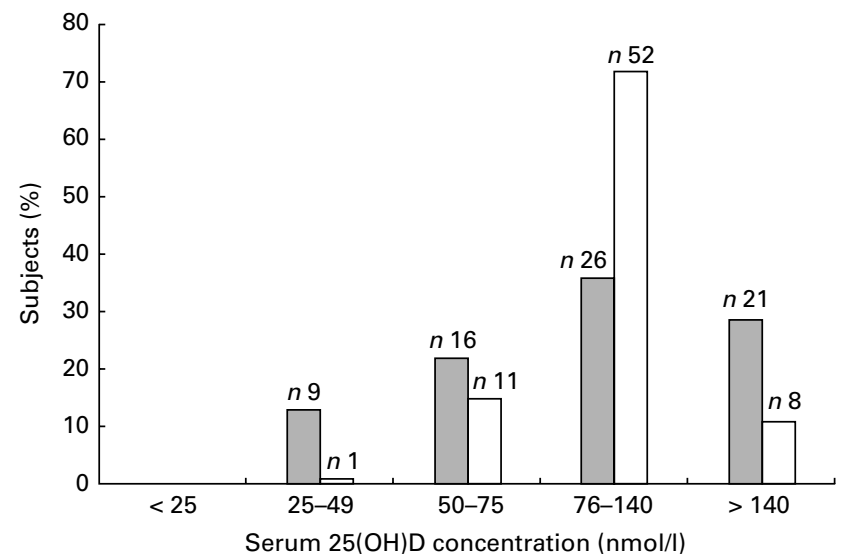

Fig. 1. Distribution of 25-hydroxyvitamin $D(25(\mathrm{OH}) \mathrm{D})(\mathrm{nmol} / \mathrm{l})$ among the seventy-two tuberculosis (TB) patients ( $\square$ ) and seventy-two controls ( $\square$ ). The overall mean, median, standard deviation, minimum and maximum of the serum 25(OH)D concentration were 108, 93, 60, 28 and 370 for the TB patients and $110,107,38,39$ and 260 for the controls.

adjusting for 25(OH)D and ethnicity. BMI, smoking, intake of fish, seal and whale meat, social status and concomitant disease (thirteen individuals had hypertension, chronic obstructive lung disease, rheumatic disorders, epilepsy, mental retardation, HIV, psychiatric disorders or eye problems) were not associated with TB.

Fig. 1 shows the distribution of 25(OH)D. Mild deficiency $(25-49 \mathrm{nmol} / \mathrm{l})$ was observed in $13 \%$ of the patients and $1 \%$ of the controls, whereas insufficiency $(50-75 \mathrm{nmol} / \mathrm{l})$ was found in $22 \%$ of the patients and $15 \%$ of the controls. No individuals had severe deficiency $(<25 \mathrm{nmol} / \mathrm{l})$. As there was only one control with $25(\mathrm{OH}) \mathrm{D}<50 \mathrm{nmol} / \mathrm{l}$, the categories $<50$ $\mathrm{nmol} / \mathrm{l}$ and $50-75 \mathrm{nmol} / \mathrm{l}$ were merged into the one category.

Table 1 shows the distribution of patients and controls in groups of low $(<75 \mathrm{nmol} / \mathrm{l})$, normal $(76-140 \mathrm{nmol} / \mathrm{l})$ and high $(>140 \mathrm{nmol} / \mathrm{l}) 25(\mathrm{OH}) \mathrm{D}$ concentrations together with adjusted and unadjusted OR and 95\% CI. After adjusting for ethnicity and alcohol, the association between $25(\mathrm{OH}) \mathrm{D}$ and risk of $\mathrm{TB}$ was U-shaped, with an OR of $6.5(95 \%$ CI $1 \cdot 8,23.5)$ among individuals with a $25(\mathrm{OH}) \mathrm{D}$ concentration $<75 \mathrm{nmol} / 1$, and an OR of 6.5 (95\% CI $1.9,22 \cdot 2)$ among those with a concentration $>140 \mathrm{nmol} / \mathrm{l}$, when compared with individuals presenting concentrations between 76 and $140 \mathrm{nmol} / \mathrm{l}$. The OR did not change considerably when adjusting for ethnicity, BMI, smoking, alcohol, intake of fish, seal and whale meat, social status or concomitant disease.
Restricting the analysis to Inuit pairs only ( $n$ 47) resulted in a similar association pattern. We observed no associations between $25(\mathrm{OH}) \mathrm{D}$ and any of the above variables. Analyses with alternative cut-off points showed that the U-shaped association pattern was not dependent on the chosen categorisation.

An estimation of the effect of supplementing individuals with low $25(\mathrm{OH}) \mathrm{D}(<75 \mathrm{nmol} / \mathrm{l})$ to normal concentrations $(76-140 \mathrm{nmol} / \mathrm{l})$ showed that the number of TB cases could be reduced by $29 \%$ when assuming a causal effect.

\section{Discussion}

The present study demonstrated that active TB was associated with both low and high concentrations of vitamin D.

Low vitamin $\mathrm{D}$ concentrations being associated with a higher risk of TB has been observed previously from different parts of the world ${ }^{(8,13,15,16)}$. The association may reflect a causal relationship, but the direction cannot be determined from the present design. However, given that the active metabolite of vitamin $\mathrm{D}, 1,25(\mathrm{OH})_{2} \mathrm{D}$, modulates macrophage function and improves the ability of macrophages to inhibit the growth of the mycobacteria ${ }^{(5,15)}$, it is likely that low vitamin $\mathrm{D}$ concentrations increase the susceptibility to $\mathrm{TB}^{(15)}$. Once an individual has become infected and developed active $\mathrm{TB}$, less exposure to sunlight ${ }^{(17)}$ while confined more to indoor life, and impaired appetite as a consequence of the infection $^{(18)}$, may contribute to low $25(\mathrm{OH}) \mathrm{D}$ concentration through reduced vitamin D synthesis in the skin and reduced food intake.

An association between high serum $25(\mathrm{OH}) \mathrm{D}$ and $\mathrm{TB}$ in a human population has, to our knowledge, not been described previously. However, the phenomenon of high (and low) $25(\mathrm{OH}) \mathrm{D}$ has been associated with prostate cancer ${ }^{(19)}$, although other limits for low $(\leq 19 \mathrm{nmol} / \mathrm{l})$ and high ( $\geq 80 \mathrm{nmol} / \mathrm{l}$ ) concentrations were used. The authors suggested that high plasma and intracellular $25(\mathrm{OH}) \mathrm{D}$ stimulates intracellular 24-hydroxylase which rapidly degrades $1,25(\mathrm{OH})_{2} \mathrm{D}$ to the inactive $1,24,25$-trihydroxyvitamin $\mathrm{D}$ resulting in low concentrations of intracellular $1,25(\mathrm{OH})_{2} \mathrm{D}^{(19,20)}$ which, again, results in increased proliferation of malignant cells. This would result in increased prostate cancer risk.

A similar mechanism may apply in the present study. High $25(\mathrm{OH}) \mathrm{D}$ concentration may lead to stimulation of 24-hydroxylase, which degrades $1,25(\mathrm{OH})_{2} \mathrm{D}$ and $25(\mathrm{OH}) \mathrm{D}$ to their 24-hydroxylated inactive forms. This would

Table 1. Unadjusted and adjusted (for alcohol and ethnicity) risk for tuberculosis according to serum hydroxyvitamin $\mathrm{D}(25(\mathrm{OH}) \mathrm{D})$ (nmol/l) groups

(Odds ratios and $95 \%$ confidence intervals)

\begin{tabular}{|c|c|c|c|c|c|c|c|c|c|c|}
\hline \multirow[b]{2}{*}{$25(\mathrm{OH}) \mathrm{D}(\mathrm{nmol} / \mathrm{l})$ group } & \multicolumn{2}{|c|}{ Patients } & \multicolumn{2}{|c|}{ Controls } & \multicolumn{3}{|c|}{ Unadjusted } & \multicolumn{3}{|c|}{ Adjusted } \\
\hline & $n$ & $\%$ & $n$ & $\%$ & OR & $95 \% \mathrm{Cl}$ & $P^{*}$ & OR & $95 \% \mathrm{Cl}$ & $P^{*}$ \\
\hline$<75$ & 25 & 35 & 12 & 17 & $5 \cdot 3$ & $1 \cdot 9,15 \cdot 3$ & $<0.001$ & $6 \cdot 5$ & $1 \cdot 8,23.5$ & 0.003 \\
\hline $76-140$ & 26 & 36 & 52 & 72 & 1 & Reference & & 1 & Reference & \\
\hline$>140$ & 21 & 29 & 8 & 11 & $5.3 \dagger$ & $1 \cdot 9,15 \cdot 3$ & & $6.5 \dagger$ & $1 \cdot 9,22 \cdot 2$ & \\
\hline
\end{tabular}

* Test for homogeneity according to $25(\mathrm{OH}) \mathrm{D}(\mathrm{nmol} / \mathrm{l})$

$\dagger$ Test for homogeneity between $>140 \mathrm{nmol} / \mathrm{l}$ and $76-140 \mathrm{nmol} / \mathrm{l}: P=0.02$ (unadjusted) and $P=0.03$ (adjusted). 
result in low $1,25(\mathrm{OH})_{2} \mathrm{D}$ concentrations and a probably increased risk of TB. Alternatively, increased $1,25(\mathrm{OH})_{2} \mathrm{D}_{3}$ concentrations might lead to down-regulation of vitamin D receptor expression resulting in defective vitamin $\mathrm{D}$ receptor signalling as previously suggested ${ }^{(21)}$.

We speculate that the association between high vitamin $\mathrm{D}$ and TB could be confounded by $n-3$ fatty acids which are largely gained from the same dietary sources as vitamin D. Experimental studies ${ }^{(22,23)}$, although presenting contradictory findings, indicated that $n-3$ fatty acids impair the immune response against $M$. tuberculosis. A recent study showed that transgenic mice enriched in $n-3$ fatty acids were more susceptible to $M$. tuberculosis than wild-type mice ${ }^{(22)}$. Thus, high levels of $n-3$ fatty acid may play a role in increasing the risk of TB.

Vitamin A is another factor that might affect the risk of TB. Individuals in the group of high vitamin D level may also have an excessive level of vitamin A as a result of a high intake of traditional food, possibly including liver from sea mammals. Vitamin A supplementation in animal studies has shown that a chronic excess of vitamin A may depress cellular and humoral immune responses ${ }^{(24)}$. Accordingly, it has been hypothesised that vitamin A supplementation of children with adequate vitamin A stores might cause a temporary immune dysregulation and lead to increased susceptibility to infectious diseases ${ }^{(25)}$. This concurs with the finding that vitamin A supplementation reduced the incidence of acute lower respiratory tract infections in children with poor nutritional status, but increased it in children with normal nutritional status ${ }^{(24)}$. Thus, concomitant excess of vitamin A might have contributed to the high risk of TB.

The U-shaped association between vitamin $\mathrm{D}$ and $\mathrm{TB}$ suggests that population-based vitamin D supplementation might not be suitable in Greenland, as supplementation of non-deficient individuals may result in a vitamin D concentration which could give a higher risk of TB. However, when assuming a causal effect, our data indicate that supplementation of deficient individuals would have beneficial effects, as increasing the vitamin D concentration from low to normal was estimated to result in a $29 \%$ reduction in the number of TB cases. Larger and prospectively designed studies are needed to determine the direction of a possible cause-effect relationship between vitamin D and TB.

\section{Acknowledgements}

We thank the study participants for their collaboration, and the staff at the district hospitals for valuable assistance. Medical student Melanie Veber is thanked for assistance in the creation of the database. The study was supported by a grant from The Greenland Home Rule Health Department.

K. L. and T. S. designed and conducted the research. B. S. was involved in the creation of the database. N. O. N. wrote the paper and had the primary responsibility for the final content. M. A. and J. W. analysed the data. A. K. and M. M. participated in the interpretation of the results. All authors read and approved the final manuscript.

The authors have no conflicts of interest.

\section{References}

1. Søborg C, Søborg B, Pouelsen S, et al. (2001) Doubling of the tuberculosis incidence in Greenland over an 8-year period (1990-1997). Int J Tuberc Lung Dis 5, 257-265.

2. Chief Medical Officer in Greenland (2007) Annual Report from the Chief Medical Officer in Greenland 2007 (in Greenlandic and Danish). Nuuk: Office of the Chief Medical Officer. http:// dk.nanoq.gl/Emner/Landsstyre/Departementer/Landslaegeembedet/Udgivelser/Aarsberetning/Aarsberetning\%202007.aspx

3. Fenton MJ (1998) Macrophages and tuberculosis. Curr Opin Hematol 5, 72-78.

4. Rockett KA, Brookers R, Udalova I, et al. (1998) 1,25Dihydroxyvitamin $\mathrm{D}_{3}$ induces nitric oxide synthase and suppresses growth of Mycobacterium tuberculosis in a human macrophage-like cell line. Infect Immun 66, 5314-5321.

5. Liu PT \& Modlin RL (2008) Human macrophage host defence against Mycobacterium tuberculosis. Curr Opin Immunol 20, 371-376.

6. Davies PD (1995) Tuberculosis and migration. The Mitchell Lecture 1994. J R Coll Physicians Lond 29, 113-118.

7. Wilkinson RJ \& Pasvol G (1995) Tuberculosis, HIV, hormones and children. $J$ R Coll Physicians Lond 29, 86-88.

8. Nnoaham KE \& Clarke A (2008) Low serum vitamin D levels and tuberculosis: a systematic review and meta-analyses. Int $J$ Epidemiol 37, 113-119.

9. Bjerregaard P (2001) Rapid socio-cultural change and health in the Arctic. Int J Circumpolar Health 60, 102-111.

10. Keiver KM, Draper HH \& Ronald K (1987) Vitamin D metabolism in the hooded seal (Cystophora cristata). J Nutr 118, 332-341.

11. Rejnmark L, Jørgensen ME, Pedersen MB, et al. (2004) Vitamin $\mathrm{D}$ insufficiency in Greenlanders on a westernized fare: ethnic differences in calcitropic hormones between Greenlanders and Danes. Calcif Tissue Int 74, 255-263.

12. Haderslev KV, Jeppesen PB, Sorensen HA, et al. (2003) Vitamin D status and measurements of markers of bone metabolism in patients with small intestinal resection. Gut 52, 653-658.

13. Friis H, Range N, Pedersen ML, et al. (2008) Hypovitaminosis D is common among pulmonary tuberculosis patients in Tanzania but is not explained by the acute phase response. J Nutr 138, 2474-2480.

14. Vieth R (2006) What is the optimal vitamin D status for health? Prog Biophys Mol Biol 92, 26-32.

15. Chan TYK (2000) Vitamin D deficiency and susceptibility to tuberculosis. Calcif Tissue Int 66, 476-478.

16. Wilkinson RJ, Llewelyn M, Toossi Z, et al. (2000) Influence of vitamin $\mathrm{D}$ deficiency and vitamin $\mathrm{D}$ receptor polymorphisms on tuberculosis among Gujarati Asians in west London: a casecontrol study. Lancet 355, 618-621.

17. Holick MF \& Chen TC (2008) Vitamin D deficiency: a worldwide problem with health consequences. Am J Clin Nutr 87, 1080S-1086S.

18. Toth A, Fackelmann J, Pigott W, et al. (2004) Tuberculosis prevention and treatment. Can Nurse 100, 27-30.

19. Tuohimaa P, Tenkanen L, Ahonen M, et al. (2004) Both high and low levels of blood vitamin D are associated with a higher prostate cancer risk: a longitudinal, nested case-control study in the Nordic counties. Int J Cancer 108, 104-108.

20. Miller GJ \& Stableton GE (1995) Vitamin D receptor expression, 24-hydroxylase activity, and inhibition of growth by $1 \alpha, 25$-dihydroxyvitamin $\mathrm{D}_{3}$ in seven human prostatic carcinoma cell lines. Clin Cancer Res 1, 997-1003.

21. Selvaraj P, Prabhu Anand S, Harishankar M, et al. (2009) Plasma 1,25 dihydroxy vitamin $\mathrm{D}_{3}$ level and expression of vitamin $\mathrm{D}$ receptor and cathelicidin in pulmonary tuberculosis. J Clin Immunol 29, 470-478.

22. Bonilla DL, Fan YY, Chapkin RS, et al. (2010) Transgenic mice enriched in omega-3 fatty acids are more susceptible to 
pulmonary tuberculosis: impaired resistance to tuberculosis in fat-1 mice. J Infect Dis 201, 399-408.

23. Jordao L, Lengeling A, Bordat Y, et al. (2008) Effects of omega-3 and -6 fatty acids on Mycobacterium tuberculosis in macrophages and in mice. Microbes Infect 10, 1379-1386.

24. Chen H, Zhuo Q, Yuan W, et al. (2008) Vitamin A for preventing acute lower respiratory tract infections in children up to seven years of age. Cochrane Database of Systematic Reviews, issue 1, CD006090. http://www.mrw.interscience. wiley.com/cochrane/clsysrev/articles/CD006090/frame.html

25. Grotto I, Mimouni M, Gdalevich M, et al. (2003) Vitamin A supplementation and childhood morbidity from diarrhea and respiratory infections: a meta-analysis. $J$ Pediatr 142, 297-304. 